\title{
Assessment of small-scale landslide treatment in Nepal
}

\author{
P. Mathema ${ }^{1}$ and J. Joshi ${ }^{2}$
}

\begin{abstract}
Landslides are major natural hazards in Nepal, and efforts are underway to treat smallscale landslides with people's participation. The main purpose of this study was to assess various aspects of the prevalent practice of landslide treatment followed by the Department of Soil Conservation and Watershed Management, Government of Nepal. Questionnaire survey and case study methods were used to collect the necessary information. It appears that the landslide treatment has been successful in stabilizing the major portion of the treated landslides. However, landuse improvement above the treated landslides, and drainage management inside and around the treated landslide sites were found to be inadequate. Also, the maintenance of constructed structures and vegetation was not satisfactory. The findings and recommendations of this paper will be useful in improving the landslide treatment in Nepal.
\end{abstract}

Keywords: Drainage management, landslide treatment, landuse improvement, people's participation

Fragile geology, rugged topography, and steep slopes combined with intense monsoonal rainfall regime and human activities create predisposing conditions for the occurrence of landslides in Nepal. Landslides are one of the most common natural hazards in the country (Upreti and Dhital, 1996). Bhandary et al. (2006) reported that the average number of small and big landslides in Nepal numbered up to 12,000 per year. An aerial counting of landslides along the flight line of an aeroplane covering about $3.5 \mathrm{~km}$ wide transect revealed that about $74 \%$ of landslides occurred under natural conditions, and only $26 \%$ of landslides were considered to be due to human activities (Laban, 1979). The estimated landslides per $100 \mathrm{~km}^{2}$ in the High Mountains, Middle Mountains and the Siwaliks were 58, 34 and 35, respectively (Sthapit, 1996, modified after Laban, 1979). Significant damage to life and property occurs as a result of landslides. Disaggregated official data on lives lost due to landslides is not available, but floods and landslides together claimed an average of 304 human lives annually between 1986 and 2005. This figure represented a third of the total lives lost due to all natural disasters (Upreti and Thapa, 2007). Such hazard figures call attention to an urgent need to stabilize the unstable slopes and mitigate landslide disasters.

Landslide treatment is carried out to mitigate landslide disasters. Landslide treatment refers to the vegetative and structural measures applied to the landslide and its immediate catchment. Properly designed and implemented landslide treatments can protect life and property as well as play an important role in soil conservation and watershed management. The Department of Soil Conservation and Watershed Management (DSCWM), Government of Nepal has been implementing landslide treatments through different Watershed Management Projects (WMPs) and District Soil Conservation Offices (DCSOs). The Department has also published a guideline (DSCWM, 2001) which spells out the scope and working strategy of all soil conservation and watershed management activities including landslide treatment. Such activities are carried out with the participation of the local people organized into user groups. As such, only small-scale landslides are treated; treatment of large landslides has remained outside the scope of the Departmental activities. By Fiscal Year 2006/07, 580 landslides had been treated (DSCWM, 2007).

It has been reported from the field that landslide treatment activities implemented by different WMPs and DSCOs in the past seem to be effective in stabilizing the treated slopes. Although many studies have been conducted on the topic of landslide hazards and damages, a systematic and detailed study on various aspects of landslide treatment has been lacking. It was realized that such a study would be useful to identify areas for improving the technological package for landslide treatment. In this context, this study on landslide treatment was

\footnotetext{
Department of Forest Research and Survey, Kathmandu, Nepal. E-mail: mathema7@yahoo.com

2 Department of Soil Conservation and Watershed Management, Kathmandu, Nepal. E-mail: jagannathjoshi@hotmail.com
} 
undertaken to examine the technical, institutional, economic and environmental aspects of landslide treatment currently practiced in Nepal.

\section{Methods}

Two methods were used in this study: questionnaire survey and case study. District Soil Conservation Officers participated in the questionnaire survey that provided information on site selection criteria; survey, mapping, design, and cost estimation; implementation process; and institutional, economic as well as environmental aspects of landslide treatment.

For the case study, the selected sites were visited, and various dimensions of the landslide were recorded. The techniques used to treat the landslide were investigated carefully and their effectiveness to stabilize the site was assessed. Semi-structured interviews were conducted to obtain detailed and specific information from the concerned group members or from individuals by using a checklist. Secondary data and information were gathered from the available publications and photograph collection of DSCWM and concerned DSCOs.

The following landslide treatment sites were selected for case study: Sisneghari landslide, Gagalphedi-3, Kathmandu; Naikap landslide, Naikap Puranobhanjyang-9, Kathmandu; and Kunchhal landslide, Bajrabarahi-3, Makawanpur. Table 1 shows the main characteristics of the landslides at the study sites.

This study covered only the landslide areas treated by DSCOs and/or projects within DSCWM. Field study was limited to the Middle Mountains physiographic zone of the Central Development Region. Although the landslide sites in other physiographic zones and development regions could not be examined for lack of time and budget constraints, the District Soil Conservation Officers participating in the questionnaire survey represented several development regions and physiographic zones.

\section{Results and discussion}

\section{Prevalent landslide treatment practices}

Site selection: Topographical and geomorphological criteria considered by the DSCO staff for landslide treatment were: depth of debris or soil, and steepness of the slope. Socio-economic criteria considered were: demand of local people, possibility of people's participation, budget limitation, extent of impact on people's livelihood, and the number of households that were vulnerable to landslide disaster. Priority was given to the poor, Dalit and Janajati community's demands while deciding landslide treatment sites. The environmental criteria considered were: sensitiveness of the slope to erosion/mass movement, potential for downstream damage, mainly agricultural field, settlement, road and other infrastructure. Only active and small landslides were considered for treatment; big and deep-seated landslides were not considered for treatment. Priority was given to the sites where low cost bioengineering techniques could be effective for slope stabilization.

Survey, design and cost estimation: While surveying, the following parameters are measured: length and width of landslide, slope angle and length, and drainage length and width. After this a sketch map is prepared; detailed technical drawings are generally not prepared. Nor are topographic maps used for locating the landslide sites. One or two DSCO staff, mainly mid-level technicians (MLTs), and two to five concerned users are involved in the

Table 1: Characteristics of the landslide at the case study sites

\begin{tabular}{llll}
\hline & $\begin{array}{l}\text { Sisneghari landslide } \\
\text { treatment site }\end{array}$ & Naikap landslide treatment site & $\begin{array}{l}\text { Kunchhal landslide } \\
\text { treatment site }\end{array}$ \\
\hline $\begin{array}{l}\text { Landslide type } \\
\text { Causal factor }\end{array}$ & $\begin{array}{l}\text { Rotational } \\
\text { Toe cutting by road and } \\
\text { rainfall }\end{array}$ & $\begin{array}{l}\text { Translational } \\
\text { Toe cutting by stream and rainfall }\end{array}$ & $\begin{array}{l}\text { Translational } \\
\text { Toe cutting by gully and } \\
\text { rainfall }\end{array}$ \\
$\begin{array}{l}\text { Year of occurrence } \\
\text { Year of treatment }\end{array}$ & 1997 & 1997 with frequent re-occurrences & 1988 \\
Average length (head & 1999 & 2001 & 1989 \\
to toe, m) & 42 & 20 & 45 \\
Average width $(\mathbf{m})$ & 39 & & \\
Surface area $\left(\mathbf{m}^{\mathbf{2}}\right)$ & 1638 & 46 & 40 \\
Slope (degree & 35 & 920 & 1800 \\
Slope type & Concave & 38 & 35 \\
\hline
\end{tabular}


field survey work. The District Soil Conservation Officers reported that there was no systematic documentation system in DSCO. Only sketch maps, section drawings and treatment design drawings were included in the estimate file. Topography, local geology, location of the landslide on the slope, steepness of slope, thickness of debris or soil, soil texture, biotic influence, and drainage system are mainly considered in designing landslide treatment. It was reported that the following items constituted the major part of treatment cost: toe wall construction, drainage construction, Gabion box checkdam construction, grass/bamboo plantation, and protection of landslide site.

Selection of landslide treatment techniques: The initiative for landslide treatment is usually taken by the affected local people. Sometimes, even DSCO staff and local community leaders take the initiative. The local people or the community submit an application to DSCO, requesting landslide protection; then DSCO staff visit the concerned site, carry out a simple feasibility study, and conduct meetings with local people/community. If DSCO staff and local community reach an agreement, MLTs and the people carry out survey of the area, and finally determine the activities and techniques to be implemented. Techniques to be applied are determined based on the requirement of site to be treated. Drainage construction/management is included if water is flowing inside the landslide area. Toe wall/retaining wall construction is included if toe cutting problem exists. Bamboo and grass plantation on exposed soil or debris deposition areas is also usually included.

Institutional aspects: Both registered and informal local groups are involved in landslide treatment. There are some provisions for maintenance by using local resources. Sometimes, resources of other agencies are also used. Some user groups have also initiated other activities like: tree plantation on erosion prone

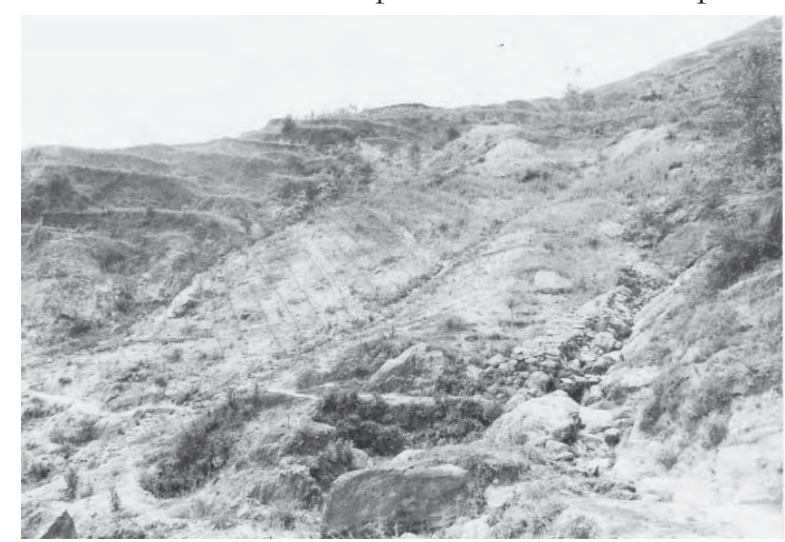

areas, grass plantation, grazing control/stall feeding, and advocacy and extension of their work. Poor, Dalit and Janajati groups are also included as group members if they are affected by the concerned landslide.

Environmental aspects: The District Soil Conservation Officers reported the following beneficial effects of landslide treatment on the natural environment: slope stabilization; reduction in soil erosion; increase in vegetative cover/promotion of greenery; biodiversity enhancement (increased number of indigenous plant species); and improvement in downstream water quality at a microcatchment level.

Economic aspects: Landslide treatment indirectly helps in income generation by protecting farm lands. Some local people also find work as wage laborers while constructing the engineering structures. In addition, after the landslide has been treated, the people feel safe from future disasters. Some District Soil Conservation Officers have rightly pointed out the need for specific studies on the economic aspects of landslide treatment.

\section{Case studies}

\section{Sisneghari landslide treatment site, Gagalphedi-3, Kathmandu}

This landslide damaged Mr. Mohan Lama's paddy field and about $40 \mathrm{~m}$ road section. The local people and Bagmati Watershed Management Project/DSCO Kathmandu agreed to stabilize the landslide. Toe wall and surface drainage in herringbone pattern within the landslide were constructed, and broom grass (Thysanolaena maxima) and bamboo were planted (Photo 1). After the treatment, the major portion of the landslide has been stabilized due to the growth of broom grass, bamboo and local plant species (Photo 2). Unfortunately, a new landslide had set off

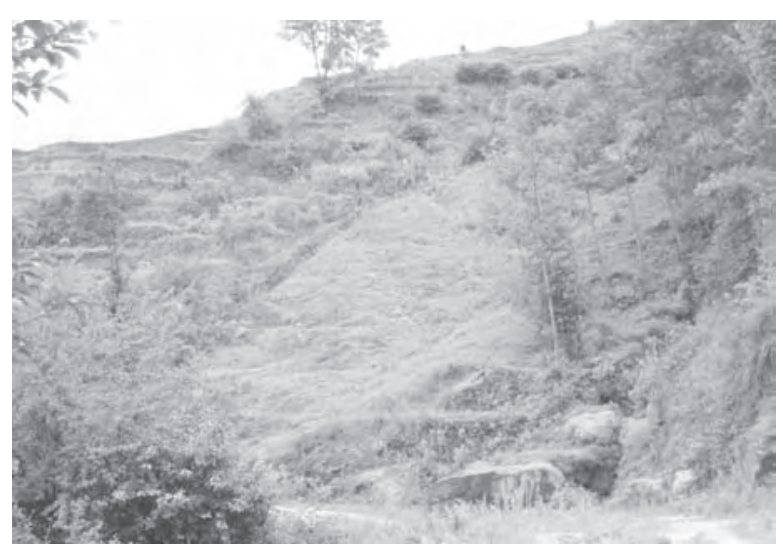

Photo 1 and 2 : Treated landslide in Sisneghari, Gagalphedi-3, Kathmandu in 1998 and 2008 
about $70 \mathrm{~m}$ above the head scarp of the treated landslide. Mr. Lama is still continuing paddy cultivation in his field just above the head scarp. There is an irrigation channel just $30 \mathrm{~m}$ above the head scarp of the treated landslide, water flows from west to east towards a natural drain. Also, excess water from the paddy field has been flowing through the treated landslide. As a result, a parcel of sloping land, $20 \mathrm{~m}$ long and $17 \mathrm{~m}$ wide, has been destabilized at the western flank of the treated landslide due to unmanaged drainage. Besides, numerous rat holes have sprung up at the western scarp where broom grass had grown well. Rats had damaged the paddy field of the farmer, so he had burnt all the clumps of broom grass in March, 2008. But the grass had grown back after the rainfall in June 2008. No maintenance work seems to have been done in the treated landslide site. The main issue here is: how to change the landuse in the catchment of the landslide, and how to ensure regular maintenance?

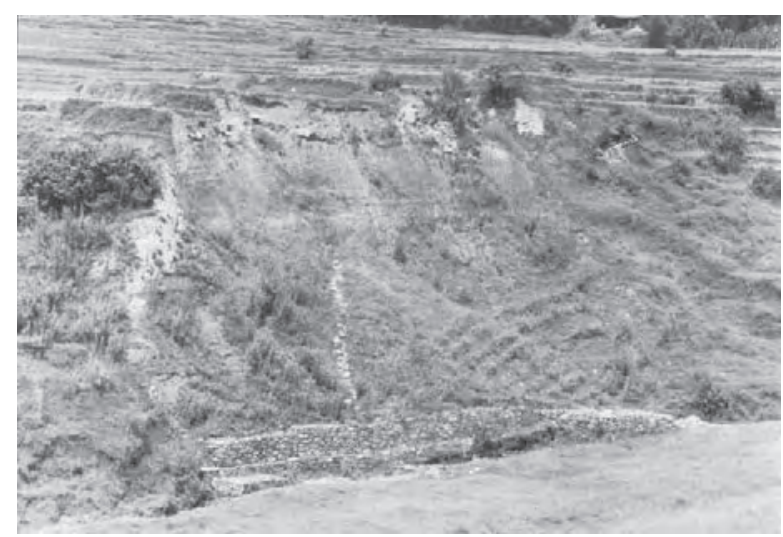

\section{Naikap landslide treatment site, Naikap Puranobhanjyang-9, Kathmandu}

This landslide damaged valuable paddy fields above the head scarp area. The affected farmers approached Bagmati Watershed Management Project/DSCO Kathmandu for assistance. The Project agreed to treat the landslide. Toe wall and surface drain within the landslide were constructed. Broom grass and utis (Alnus nepalensis) were planted (Photo 3). After the treatment, the major portion of the landslide had been stabilized. Broom grass and local plant species had grown up. Some utis trees were growing on the upper side of the landslide (Photo 4). However, excess water from the paddy fields above had entered the treated landslide. As a result, erosion had started at the lower side of the treated landslide. No maintenance work seems to have been done in the treated landslide area. The main issue here is: how to change the present landuse in the catchment of the landslide, and how to ensure regular maintenance?

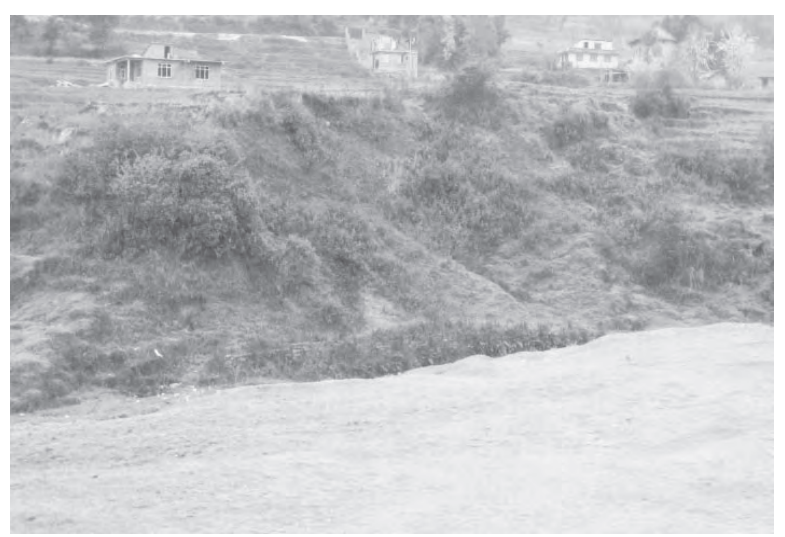

Photo 3 and 4 : Treated landslide in Naikap Puranobhanjyang-9, Kathmandu in 2001 and 2008

\section{Kunchhal landslide treatment site, Bajrabarahi-3, Makawanpur}

This landslide damaged agricultural land and a section of the road to Kulekhani Hydroelectric reservoir (Photo 5). Kulekhani Watershed Management Project treated the landslide by constructing a toe wall and a series of checkdams, and by planting utis seedlings (Photo 6 and 7). After the treatment, the landslide was completely stabilized, and the utis trees and other indigenous plants grew quite well (Photo 7). The agricultural land in the deposition zone just behind the toe wall had been reclaimed and the farmer had even started cultivation. The main issue here is related to the ownership, management and utilization of trees and grasses growing in the treated area.
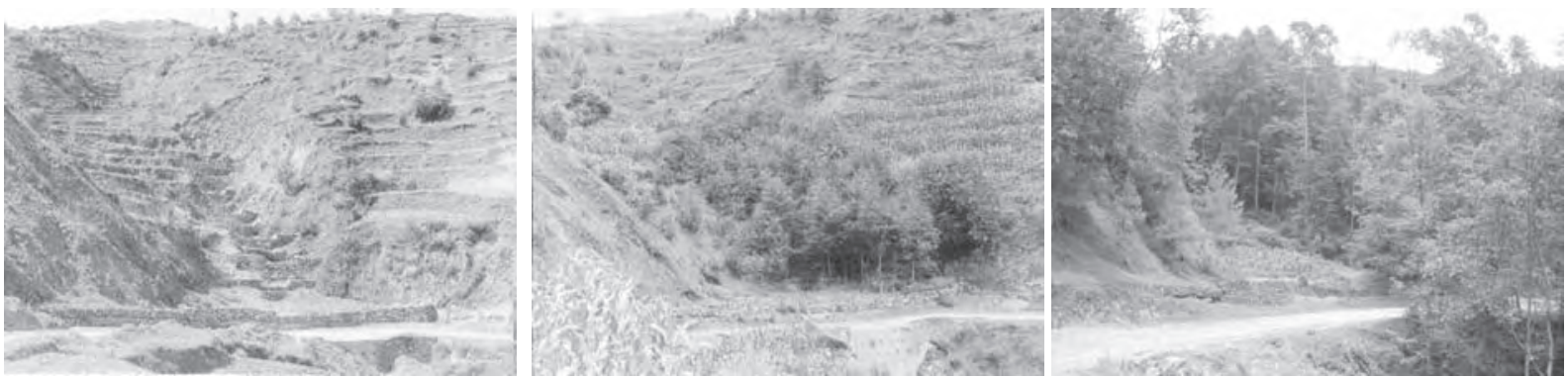

Photo 5, 6 and 7 : Treated landslide in Kunchhal, Bajrabarahi-3, Makawanpur in 1989, 1995 and 2008 


\section{Techniques used for landslide treatment}

It was observed that different techniques had been applied to treat the various landslides, depending on site characteristics and type of landslides.

- toe wall construction (loose stone and stone filled Gabion boxes)

- drainage management inside the landslide

- checkdam construction

- bamboo, grass and tree species plantation

- protection of the treated area from grazing

These techniques have proved to be effective in stabilizing the major portion of the treated landslides. However, landuse improvement and drainage management in the catchment area of landslide were not detected in any of the landslide treatment sites. Also, grazing control was ineffective in some sites. Although the scope of landslide treatment involves a complete package, (including construction of diversion channels around and inside the landslide, structural erosion control measures, vegetative measures, landuse improvement in the catchment area, construction of pond to store and divert excess run-off, protection of the site from grazing and other detrimental activities), such a complete treatment was wanting in all study sites.

\section{Problems}

Although a number of benefits-slope stabilization, increased greenery, protected farmland above and below the treated landslides-were observed, the following problems were noticed in the course of the field study:

- Inappropriate drainage management: Drainage management was not done above the head scarp and crack zone of landslide (all sites). Excess water from rice fields drained through the landslide area (all sites).

- Inappropriate landuse above the treated landslides: Rice cultivation just above crack zone of landslide (all sites).

- Detrimental biotic interference inside the treated areas: Burning of planted grasses on landslide treatment site (all sites); allowing goat grazing inside landslide areas (Sisneghari and Gagalphedi); road-cuttings without conservation measures (Sisneghari, and Gagalphedi). Rat holes were noted on the head scarp of the landslide (Sisneghari, and Gagalphedi).

- Lack of regular maintenance (all sites).
The major problems highlighted by the respondent District Soil Conservation Officers were: insufficient budget to meet people's demand and to cover the entire landslide area; lack of ownership of the treated areas by the local community resulting in inadequate maintenance; and inadequate implementation capacity due to insufficient number of MLTs.

\section{Conclusions and recommendations}

Landslide treatment seems to be successful in stabilizing the major portion of the treated landslides. However, drainage management is still inadequate or improper thus resulting in erosion in the crack zone, main scarp and side scarps which could destabilize the slope in the future. In addition, maintenance of constructed structures and vegetation seemed to be less than adequate. The following recommendations are, therefore, made:

- More detailed site investigation should be done before designing landslide treatments. Details on site assessment method can be found in Mathema and Joshi (2008).

- A complete technological package should be implemented to treat landslides with multi-year planning and intervention.

- There is a need for training of MLTs to improve the knowledge and skills regarding landslide treatments. A specific guideline in Nepali language on landslide treatment is needed. This guideline could contain criteria for grouping landslides for different treatment options. A possible grouping could be as follows:

- farm level landslides to be treated by the concerned farmer(s) with technical guidance of DSCO staff;

- small landslides to be treated by the local community in partnership with DSCO/other organizations;

- big landslides threatening nationally important infrastructure to be treated by DSCWM, DSCO and other concerned organizations, as a special programme with adequate budget allocation

- buge landslides resulting from tectonic causes: treatment not advisable

- Above all, there is an urgent need for awareness raising programme to encourage the adoption of appropriate landuse practices in the catchment of landslides. 


\section{References}

Bhandary N. P., Yatabe, R., Hasegawa, S., Inagaki, H. and Shrestha, H.K. 2006. Characterization of Landslides and Roadside Slope Failures along the Highways in Central Nepal. Proceedings of International Symposium on Geo-disasters: Infrastructure Management and Protection of World Heritage Sites, 2526 November 2006, Kathmandu, Nepal. p. 135.

DSCWM. 2001. Soil Conservation and Watershed Management Activities (Definition, Objective, Scope and Working Strategy). Department of Soil Conservation and Watershed Management, Kathmandu, Nepal.

DSCWM. 2007. Annual Report FY 2062/63. Department of Soil Conservation and Watershed Management, Kathmandu, Nepal.

Laban, P. 1979. Landslide Occurrence in Nepal. Department of Soil Conservation/Integrated Watershed Management, Torrent Control and Land Use Development Project, Kathmandu.
Mathema, P. and Joshi, J. 2008. Study on Landslide

Treatment. Department of Soil Conservation and Watershed Management, Kathmandu, Nepal.

Sthapit, K.M. 1996. Soil Erosion Problems in Nepal. In: Space Informatics for Mountain Resources Management. Proceedings of the Second Space Informatics Seminar for Sustainable Development: Mountain Resources Management. 2-6 December 1996, Kathmandu, Nepal, (ed. Asikhia, O.), UNCRD Proceedings Series, No. 21. United Nations Centre for Regional Development, Nagoya, Japan. 6190.

Upreti B.N. and Dhital, M.R. 1996. Landslide Studies and Management in Nepal. International Centre for Integrated Mountain Development, Kathmandu, Nepal.

Upreti B.N. and Thapa, P.B. 2007. Reducing Disaster Risk for Sustainable Development and Poverty Alleviation in Nepal. Proceedings of International Conference on Emerging Issues on Research and Development, April 4-6, 2007, Kathmandu, Nepal.. 